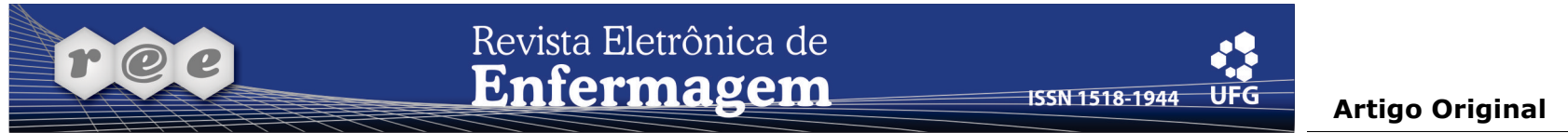

\title{
O ensino de enfermagem psiquiátrica na Escola Ana Néri, na primeira metade do século XX
}

\author{
Psychiatric nursing teaching at the Ana Nery School in the first half of the $20^{\text {th }}$ century
}

Enseñanza de enfermería psiquiátrica en Escuela Ana Néri durante la primera mitad del siglo XX

Monique da Silva Carvalho ${ }^{1}$, Gizele da Conceição Soares Martins ${ }^{2}$, Nícia Lima Dias ${ }^{3}$, Tânia Cristina Franco Santos ${ }^{4}$, Antonio José Almeida Filho ${ }^{5}$, Maria Angélica Almeida Peres ${ }^{6}$

\footnotetext{
${ }^{1}$ Enfermeira. Rio de Janeiro, RJ, Brasil. E-mail: monique_inca@outlook.com.

2 Enfermeira, Mestre em Enfermagem. Discente do Programa de Pós-Graduação em Enfermagem, nível Doutorado, da Escola de Enfermagem Anna Nery da

Universidade Federal do Rio de Janeiro (EEAN/UFRJ). Rio de Janeiro, RJ, Brasil. E-mail: gizelemartins16@hotmail.com.

${ }^{3}$ Enfermeira. Discente do Programa de Pós-Graduação em Enfermagem, nível Mestre, da EEAN/UFRJ. Rio de Janeiro, RJ, Brasil. E-mail:

nicinha.lima@gmail.com.

${ }^{4}$ Enfermeira, Doutora em Enfermagem. Professora Associada da EEAN/UFRJ. Rio de Janeiro, RJ, Brasil. E-mail: taniacristinafsc@terra.com.br.

${ }^{5}$ Enfermeiro, Doutor em Enfermagem. Professor Associado da EEAN/UFRJ. Rio de Janeiro, RJ, Brasil. E-mail: ajafilhos@gmail.com.

${ }^{6}$ Enfermeira, Doutora em Enfermagem. Professora Adjunta da EEAN/UFRJ. Rio de Janeiro, RJ, Brasil. E-mail: angélica.ufrj@uol.com.br.
}

\section{RESUMO}

O objetivo do estudo é descrever o ensino de enfermagem psiquiátrica na Escola Ana Néri (EAN), no período de 1925 a 1954. Metodologia: Pesquisa sócio-histórica cujas fontes foram documentos escritos e o depoimento oral de uma exprofessora. Utilizou-se a técnica de análise documental para tratamento dos dados. Resultados: durante 27 anos, a EAN não inseriu suas alunas no campo psiquiátrico, devido ao estigma da doença mental, oferecendo apenas disciplinas teóricas, ministradas por médicos, posteriormente teóricas com treinamento prático em sala de aula, até chegar à teórica com prática em hospital psiquiátrico e ministrada por enfermeira. Concluiu-se que a Lei 775/49 levou a EAN a especializar uma professora e a dar início à reformulação da assistência de enfermagem no Instituto de Psiquiatria da Universidade do Brasil, a fim de adequá-lo para servir de campo prático, modelo para o ensino da assistência de enfermagem psiquiátrica no Brasil.

Descritores: Enfermagem Psiquiátrica; História da Enfermagem; Educação em Enfermagem.

\section{ABSTRACT}

The aim of this study was to describe the teaching of psychiatric nursing at Ana Néri Nursing School (EAN), between 1925 and 1954. Methodology: Socio-historical research whose sources were written documents and the oral statement of an ex-professor. The documentary analysis technique was used for data treatment. Results: For 27 years, the EAN did not introduce students into the psychiatric field due to the mental illness stigma, offering only theoretical disciplines, which were taught by physicians. Later there were theoretical disciplines with practical training in the classroom, and then theoretical disciplines with practice in psychiatric hospitals, taught by nurses. In conclusion, the law $775 / 49$ lead the EAN to qualify a professor and initiate the reformulation of the nursing care provided at the Institute of Psychiatry of the University of Brazil, so as to adjust it to serve as a practical field and a model for teaching psychiatric nursing in Brazil.

Descriptors: Psychiatric Nursing; History of Nursing; Education, Nursing.

\section{RESUMEN}

Se objetivó describir la enseñanza de enfermería psiquiátrica en la Escuela Ana Néri (EAN) entre 1925 y 1954. Metodología: Investigación sociohistórica cuyas fuentes fueron documentos escritos y testimonio oral de una ex profesora. Se utilizó análisis documental para tratamiento de los datos. Resultados: Durante 27 años, la EAN no introdujo a sus alumnas en el campo psiquiátrico debido al estigma de la enfermedad mental, ofreciendo apenas disciplinas teóricas, dictadas por médicos; posteriormente, teóricas con tratamiento práctico en sala de clases, hasta llegar a teóricas con práctica en hospital psiquiátrico dictadas por enfermeras. Se concluye en que la Ley 775/49 llevó a la EAN a especializar a una profesora e iniciar la reformulación de la atención de enfermería en el Instituto de Psiquiatría de la Universidad de Brasil, a fin de adecuarlo para servir como campo práctico, modelo para la enseñanza de la atención de enfermería psiquiátrica en Brasil.

Descriptores: Enfermería Psiquiátrica; Historia de la Enfermería; Educación en Enfermería. 


\section{INTRODUÇÃO}

$O$ presente estudo tem como objeto a gênese do ensino de enfermagem psiquiátrica na Escola Ana Néri (EAN), no período de 1925 a 1954. O marco inicial corresponde ao ano de inserção da disciplina "Higiene Mental" no currículo da escola e o marco final à introdução do estágio em "Enfermagem Psiquiátrica"* .

Ao ser criada em 1922, no bojo da Reforma Sanitária promovida pelo Departamento Nacional de Saúde Pública, uma das características do ensino estabelecido no currículo da EAN era o treinamento das alunas em campo de prática, seguindo as recomendações do Sistema Nightingale, criado na Inglaterra, no século $\mathrm{XIX}^{(1)}$. Os pilares deste Sistema estabeleciam critérios dos quais destacamos: a rigorosa seleção de candidatas, a direção das escolas de enfermagem por enfermeiras, e o ensino teórico e prático metódicos ${ }^{(2)}$.

Para tanto, a EAN foi construída próximo ao Hospital Geral da Assistência, atual Hospital Escola São Francisco de Assis. Desde o início do seu funcionamento em 1923, a EAN tinha a preocupação com o provimento de campos de estágio, visto que esta atividade, que na época correspondia ao que hoje chamamos de atividade prática, era considerada indispensável à boa formação da enfermeira. Sendo assim, o Hospital São Francisco de Assis foi aparelhado para oferecer a maioria dos campos de estágio, somado ao Hospital São Sebastião, campo para o estágio em doenças transmissíveis e a um Centro de Saúde que foi organizado para o ensino prático em saúde pública ${ }^{(3-4)}$.

No que tange à psiquiatria, pode-se constatar que os locais que serviam de campo prático para a EAN não incluíam nenhum serviço psiquiátrico. Dessa forma, a escola não realizou estágio nesse campo até o ano de 1954, ou seja, durante a primeira metade do século XX, as alunas eram formadas sem a prática de cuidado com os doentes mentais ${ }^{(5)}$.

Considerando que a EAN foi elevada a escola padrão oficial do Brasil, para fins de equiparação das demais escolas de enfermagem, pelo decreto $n^{\circ} 20.109$ de 1931 , a falta de preparo das alunas para a psiquiatria, pode ser vista como um prejuízo para a prática da Enfermagem Psiquiátrica em todo o país, uma vez que não contribuía diretamente para a inserção de enfermeiras padrão nesse campo, conforme ocorreu nos serviços de saúde pública e de hospital geral. Sendo assim, até meados do século $X X$, a Enfermagem Psiquiátrica era exercida, em sua maioria, por pessoal sem preparo formal e mal remunerado ${ }^{(5-6)}$. Não obstante, o preparo de profissionais de enfermagem para a psiquiatria no Brasil, teve início em 1890 com a criação da Escola Profissional de Enfermeiros e Enfermeiras do Hospital Nacional de Alienados, que logo passou a preparar profissionais para todas as áreas assistenciais devido à carência de instituições de ensino de enfermagem no Rio de Janeiro e necessidade de mão de obra profissionalizada nos hospitais ${ }^{(5-7)}$.

O trabalho de enfermagem nos hospitais psiquiátricos era cercado de preconceitos que estavam associados ao trabalho manual exercido pela Enfermagem Psiquiátrica, quase sem nenhuma intervenção terapêutica tecnológica. As pessoas que procuravam os hospitais psiquiátricos para trabalhar deveriam se submeter às normas disciplinares que orientavam o funcionamento dos asilos, mas nem sempre esses profissionais se submetiam a tais normas e, por isso, lhes eram atribuídas características como despreparados culturalmente e despossuídos de qualquer vocação para trabalhar com doentes mentais ${ }^{(8-9)}$. Isso gerava uma alta rotatividade dos profissionais de enfermagem e a assistência acabava ficando nas mãos de atendentes, que eram pessoas que integravam a equipe de enfermagem sem nenhum preparo formal e muitas vezes semi-alfabetizados.

Portanto, as características das instituições psiquiátricas na primeira metade do século $X X$ eram as principais barreiras para o ensino da especialidade na EAN, seguida da ausência de uma professora com experiência na área, outra barreira não menos importante e que significava a ausência de um saber reconhecido que pudesse ser aplicado em demonstração às alunas ${ }^{(5)}$.

Neste contexto, a EAN optou por oferecer durante a primeira metade do século $X X$, conteúdos sobre psiquiatria apenas sob a forma teórica e teórico-prática, onde as alunas aprendiam a assistência de Enfermagem Psiquiátrica por meio de simulações em sala de aula, evitando assim, levar as mesmas para campos de estágio não preparados para o ensino de enfermagem, uma vez que a assistência de enfermagem nas instituições psiquiátricas não seguia uma metodologia compatível com os padrões e normas aplicados pela Escola(5). Diante do exposto, o objetivo deste estudo foi descrever o ensino de enfermagem psiquiátrica na EAN, no período de 1925 a 1954.

Entende-se que se faz relevante a elaboração de estudos que registrem o desenvolvimento do ensino e da
* Quando criada em 1922 a Escola de Enfermagem Anna Nery da Universidade Federal do Rio de Janeiro foi denominada Escola de Enfermeiras do Departamento Nacional de Saúde Pública, posteriormente passou a chamar- se Escola de Enfermeiras D. Ana Nery (1926), depois Escola Ana Néri (1937) e em 1965 recebeu o nome que permanece até os dias atuais. 
assistência de Enfermagem Psiquiátrica, justificada pela própria trajetória do Movimento de Reforma Psiquiátrica, onde a desconstrução e superação de práticas historicamente construídas ainda é um desafio para o ensino e para o exercício da profissão de Enfermagem. Apesar das tentativas de melhorias empregadas pela reforma psiquiátrica, ainda são necessários avanços para que o modelo manicomial não continue sendo reproduzido(10). O processo é lento porque carece de constante reflexão das práticas e referenciais teóricos adotados pelos profissionais de saúde, a fim de não se institucionalizarem dentro de uma lógica manicomial ${ }^{(11)}$. Logo, para que este modelo seja transformado, é necessário historiografar a assistência e o ensino de enfermagem em psiquiatria, já que no Brasil as publicações sobre o assunto são escassas.

Este estudo se justifica pela importância atual de se reformular o ensino de enfermagem psiquiátrica para atender à nova configuração da assistência em saúde mental advinda do movimento de reforma psiquiátrica e que nos faz olhar para o passado em busca de ideias para o planejamento do ensino na especialidade no presente e futuro.

\section{METODOLOGIA}

Para condução do estudo foi adotado o conceito de história-social. Tal conceito surgiu como uma possibilidade frente às limitações da historiografia tradicional, possível de utilização por outras ciências humanas e disciplinas, além de viabilizar tanto a ampliação de objetos como o aprimoramento metodológico. A história social, então, "passa a ser encarada como perspectiva de síntese, como reafirmação do princípio de que, em história, todos os níveis de abordagem estão inscritas no social e se interligam" (12).

As fontes primárias foram documentos escritos: legislações, artigos publicados nos Annaes de Enfermagem, "Histórico de Vida Escolar" de alunas e outros documentos institucionais, bem como 0 depoimento oral de uma ex-professora da EAN, enfermeira especializada em psiquiatria nos EUA, professora de "Enfermagem Psiquiátrica" da EAN, de 1949 até 1956, coletado em 1990 e doado ao Centro de Documentação da atual Escola de Enfermagem Anna Nery, da Universidade Federal do Rio de Janeiro para servir de fonte para outros estudos. Como fontes secundárias foram utilizados livros e artigos sobre temáticas afins ao tema do estudo como Enfermagem Psiquiátrica, História da Psiquiatria e História da
Enfermagem. A coleta de dados ocorreu no período de agosto de 2011 a agosto de 2012.

Cada documento selecionado foi examinado detalhadamente, submetido à crítica interna e externa, comparado-se a fonte oral com as fontes escritas selecionadas e seus conteúdos agrupados de acordo com a cronologia e a temática de que tratavam. A análise documental originou duas categorias centrais: "Inserção de disciplinas referentes à psiquiatria no currículo da EAN" e "Início do estágio em Enfermagem Psiquiátrica na EAN".

O projeto que deu origem ao presente estudo foi aprovado pelo Comitê de Ética em Pesquisa da Escola de Enfermagem Anna Nery/Hospital Escola São Francisco de Assis/Universidade Federal do Rio de Janeiro, em 29 de junho de 2010, tendo como protocolo o número $n^{\circ}$ $064 / 2010$.

\section{RESULTADOS}

Os dados apontaram que a EAN, em sua trajetória de liderança no país nas primeiras décadas do século $\mathrm{XX}$, tinha a responsabilidade de manter $o$ ensino de enfermagem em elevado nível técnico-profissional. Apesar disso, a escola preteriu o estágio em psiquiatria o quanto pôde. Suas alunas, por viverem em regime de internato na escola, precisavam de proteção a fim de que Ihes fosse garantida a integridade física e moral. As condições do ambiente psiquiátrico no contexto históricosocial da época poderiam interferir nessa integridade. As fontes pesquisadas permitiram descrever o surgimento e o desenvolvimento do ensino de Enfermagem Psiquiátrica na EAN, o que ocorreu de acordo com as possibilidades da Escola para propiciar um reconhecido saber, de acordo com as práticas psiquiátricas de cada período.

\section{Inserção de disciplinas referentes à psiquiatria no currículo da EAN}

As disciplinas referentes à psiquiatria que fizeram parte do currículo da EAN na primeira metade do século XX foram:

\section{Higiene Mental}

Durante os dois primeiros anos de sua existência a EAN não teve em seu programa de curso matéria alguma referente à psiquiatria ${ }^{(13)}$. A partir de 1925 , a disciplina "Higiene Mental" aparece registrada no Histórico de Vida Escolar das Alunas. Tal disciplina era ministrada por médicos, não constando nos documento pesquisados o nome do professor responsável por ministrar tal conteúdo no ano de sua introdução. No entanto, aparecem como professores de "Higiene Mental" os médicos: Plínio Olinto, 
A. Coutinho Filho, Morais Coutinho, José Leme Lopes e Joubert Torres Barbosa, todos professores da Faculdade de Medicina da Universidade do Brasil (UB), da qual a EAN também fazia parte desde $1937^{(13)}$.

Os dados apontam que as alunas que fizeram 0 segundo ano do curso em 1925 tiveram a disciplina "Higiene Mental", embora não conste em todos os históricos da mesma época a nota dessa disciplina e, em alguns documentos, exista a informação de que a mesma teve início em 1926. Sendo assim, e diante do fato da maioria dos documentos apontarem o aproveitamento, o grau obtido e o ano em que a disciplina "Higiene Mental" foi cursada, acatamos a data de 1925 como início da aplicação de conteúdo referente à psiquiatria no currículo da EAN.

Cabe ressaltar que há históricos sem nota em algumas matérias, o que pode indicar que, por alguma razão que nessa pesquisa não foi possível verificar, existiram alunas que não fizeram tal disciplina ou que a forma de registro foi precária.

Pelas circunstâncias de sua criação, a EAN tinha como filosofia formar profissionais de alto padrão, para que ocupassem lugares de destaque no campo da saúde pública $^{(9)}$. Com isso, não participou de imediato das experiências de preparação formal de pessoal de enfermagem para trabalhar em hospitais psiquiátricos e em programas de Higiene Mental, cuja implementação foi intensificada nas décadas de 1920 a $1940^{(8)}$. A formação na EAN tinha características disciplinares rígidas e o ensino contemplava a assistência de enfermagem em diversas especialidades clínicas ${ }^{(9)}$, exceto na psiquiatria. A inserção de conteúdos de psiquiatria no currículo da EAN se deu de forma gradual, começando apenas por aulas teóricas ministradas por professores médicos ${ }^{(14)}$.

A inclusão da Higiene Mental no currículo da EAN a partir de 1925 relaciona-se às tentativas de melhorar a assistência psiquiátrica, iniciadas com a fundação da Liga Brasileira de Higiene Mental (LBHM), no Rio de janeiro, em 1923, tendo como base o ideal da Psiquiatria preventiva, da Eugenia e da Higiene Mental, que viria a ser fortemente sustentado pelos psiquiatras a ela pertencentes. Assim, a LBHM colocou-se na defesa dos interesses do Estado, levando a uma ação rigorosa de controle social e trazendo aos psiquiatras um maior poder de intervenção na sociedade ${ }^{(15-16)}$.

De outro modo, por recomendar a saída do psiquiatra de dentro do asilo, levando-o para a comunidade, esse movimento manteve a psiquiatria ligada ao movimento mais amplo e mais antigo da higiene e saúde pública, em que, a política assistencial desejava a criação de campanhas, ambulatórios e serviços abertos, de forma a manter sua entrada e permanência na sociedade. O discurso da Higiene Mental deixava de lado a defesa do hospício como modelo de assistência. Entretanto, o modelo assistencial asilar permanecia e em seu interior alojava-se a população alvo da política de Higiene Mental ${ }^{(15-16)}$.

O fato de ter sido a disciplina "Higiene Mental" o primeiro conteúdo referente à psiquiatria a ser introduzido no currículo da EAN deve-se ao momento histórico do saber psiquiátrico da época. Nas primeiras décadas do século $X X$, havia uma relação favorável entre a enfermeira de saúde pública e a política de higiene mental, como vemos em um artigo publicado nos Annaes de Enfermagem em que um psiquiatra da LBHM enaltece a assistência de enfermagem psiquiátrica no consultório, no domicilio e no hospital, sendo que na prática domiciliar destacava o papel da enfermeira visitadora em fornecer instruções sobre o tratamento. Também afirmava que o papel da enfermeira de higiene mental era, frequentemente, quase tão importante como o do médico $^{(16)}$.

Logo, ao formar enfermeiras para atuar na Saúde Pública, a EAN era um campo preparatório de profissionais capazes de divulgar as ideias de prevenção das chamadas moléstias mentais, tanto assim, que um dos professores da disciplina era o psiquiatra Plínio Olinto, um dos integrantes da $\mathrm{LBHM}^{(8)}$.

\section{Psiquiatria}

A disciplina "Psiquiatria" aparece pela primeira vez no Histórico de Vida Escolar das alunas no ano de 1931, também ministrada por médicos e tornando o discurso médico o principal formador das enfermeiras da EAN nessa especialidade, o que fazia que o ensino fosse direcionado exclusivamente para as patologias e as síndromes psiquiátricas ${ }^{(5)}$. Tratava-se de uma disciplina exclusivamente teórica, ministrada no último ano do Curso de Enfermeiras e indicava a tendência hospitalocêntrica do tratamento psiquiátrico à época. A disciplina de Psiquiatria teve como primeiro professor o psiquiatra Plínio Olinto e, ao longo do período estudado, teve os mesmos professores que a disciplina "Higiene mental", com acréscimo de dois nomes: Levi J. Bittencout e Flávio de Souza.

O fato da disciplina de psiquiatria ter sido ministrada para as alunas da EAN antes da disciplina de enfermagem psiquiátrica está relacionado com o reconhecimento da Psiquiatria como especialidade médica, na Faculdade de 
Medicina do Rio de Janeiro ${ }^{+}$, desde 1883, quando ocorreu a primeiro concurso para a Cátedra de Psiquiatria(17-18). Isto permitia o acesso da EAN à professores da especialidade na Faculdade de Medicina, enquanto que não havia na Escola enfermeiras com tal conhecimento reconhecido. O fato da EAN também pertencer a UB facilitava a vinda de professores médicos para ministrar aulas.

Quando analisamos as características da disciplina 'Psiquiatria", inserida no currículo a partir de 1931, observamos um conteúdo biomédico, ministrado por psiquiatras e sem atividade prática.

\section{Enfermagem Psiquiátrica}

A "Enfermagem Psiquiátrica" entrou no currículo da EAN no ano de 1933, dez anos após o inicio de funcionamento da EAN e dois anos após o inicio das aulas de "Psiquiatria", se distinguindo das demais disciplinas específicas por possuir um segmento teórico e outro prático, ambos ministrados em sala de aula. No currículo da EAN, a Enfermagem Psiquiátrica era a única disciplina de enfermagem que não possuía estágio. Na parte prática as alunas treinavam em sala de aula como abordar e conter o doente, bem como realizar as técnicas para os tratamentos somáticos ${ }^{(5,19)}$. No entanto, o saber sobre a Enfermagem Psiquiátrica ainda estava em construção no Brasil, o que retardou a sua entrada no currículo da EAN $^{(19)}$.O distanciamento das enfermeiras diplomadas desse espaço foi um forte fator de impedimento para o desenvolvimento da Enfermagem Psiquiátrica, cuja prática manteve o aspecto meramente custodial ${ }^{(5)}$.

As professoras enfermeiras que deram aulas de Enfermagem Psiquiátrica no período estudado foram: Carrie Reno, Alaíde Carneiro, Hilda Kiseh, Ena Zoffoli, Maria José Valente e Olga Salinas Lacorte ${ }^{(19-20)}$. Durante o período de 1925 a 1949, as alunas não tiveram contato com doentes mentais na parte prática da disciplina, embora nos históricos das alunas formadas a partir do segundo semestre de 1942, ou seja, que fizeram "Enfermagem Psiquiátrica" em 1941, tenha a palavra prática ao lado do nome da disciplina. Tal prática era caracterizada por demonstrações simuladas em sala de $\operatorname{aula}^{(5,19)}$.

Ao buscar estudos que tratam da assistência psiquiátrica nas primeiras décadas do século $X X$, nos deparamos com uma assistência pautada no isolamento, através da internação em hospitais, cujas características principais eram a superlotação e um tratamento com base na contenção física ${ }^{(9,17)}$. Os serviços psiquiátricos no Brasil, desde a criação do primeiro hospício em 1852, caracterizavam-se dentro do modelo assistencial asilar, sendo o cuidado de enfermagem pautado nos procedimentos disciplinares e na manutenção da ordem institucional $^{(8,11)}$.

Tais questões impediam a realização do estágio da EAN no campo da psiquiatria, justificada pela necessidade de preservar a moral das alunas, que não deveriam ser expostas a atitudes e discursos inconvenientes que poderiam ter os pacientes psiquiátricos ${ }^{(19)}$. A disciplina Enfermagem Psiquiátrica foi inserida no currículo em 1933, com conteúdos teóricos e práticos ministrados por professoras enfermeiras em sala de aula, ou seja, as alunas diplomavam-se enfermeiras sem ter contato com o doente mental em setor especializado.

Outra característica que merece destaque é que em todos os anos do recorte temporal deste estudo, observou-se que as disciplinas referentes à psiquiatria foram ministradas sempre no último ano do curso, característica que se manteve em todas as fases e ainda é observada no atual currículo da Escola de Enfermagem Anna Nery, apesar das mudanças curriculares ocorridas ao longo dos anos.

\section{Início do estágio em Enfermagem Psiquiátrica na EAN}

Promulgada em 6 de agosto de 1949 e regulamentada pelo Decreto $n^{\circ} 27.426$ do mesmo ano, a Lei $n^{\circ} 775$ dispunha sobre o ensino de enfermagem no Brasil, com diretrizes que adequariam o ensino de enfermagem as reais necessidades de qualificação profissional. A Lei tornou oficial o curso de enfermagem e o de auxiliar de enfermagem, que deveriam ter duração de trinta e seis e dezoito meses respectivamente ${ }^{(21)}$. Além disso, a Lei retira da EAN o título de escola oficial padrão, que carregou por 18 anos, o que a levou a empreender esforços para se adequar as novas exigências legais. Com o fim do Padrão Ana Neri a fiscalização do ensino oferecido pelas escolas de enfermagem de todo o país passou a ser atribuição da Diretoria de Ensino Superior do Ministério da Educação e Saúde ${ }^{(5)}$.

De acordo com o decreto de regulamentação da Lei $775 / 49$, são especificadas as disciplinas que deveriam estar presentes no curso de enfermagem e em que série da graduação as mesmas deveriam ser ministradas. 0

\footnotetext{
${ }^{\dagger}$ Naquele momento Faculdade de Medicina da Universidade do Brasil (UB), atualmente Faculdade de Medicina da UFRJ.
} 
estágio em enfermagem psiquiátrica aparece como obrigatório e a disciplina deveria ser apresentada às alunas na segunda série do curso ${ }^{(21)}$.

Nos Annaes de Enfermagem, atual Revista Brasileira de Enfermagem, se observa que o número de publicações sobre Enfermagem Psiquiátrica era muito reduzido, o que evidencia que a especialidade era pouco discutida pelas enfermeiras e professoras da época, não sendo objeto de interesse das mesmas, o que refletia nas condições da assistência de enfermagem psiquiátrica ${ }^{(8)}$. Somente a partir de 1946 o tema Enfermagem Psiquiátrica passa a ser visto nas publicações com mais frequência, e isto se intensifica á partir de 1950, fato que podemos relacionar com a promulgação da Lei n 775 e consequente obrigatoriedade do estágio em Enfermagem Psiquiátrica, quando passou a existir uma maior necessidade de conhecimento das docentes para ministrarem tal conteúdo e acompanharem o estágio das alunas ${ }^{(5,8)}$.

Poucos autores escreviam sobre Enfermagem Psiquiátrica no período estudado, por isso existe uma grande dificuldade em encontrar textos que dizem respeito ao tema, entretanto, um deles fala da importância da disciplina para a formação das alunas, dizendo que a "Enfermagem Psiquiátrica, embora esteja incluída no programa de algumas escolas de enfermagem, foi introduzida no currículo das 38 escolas como obrigatória, só muito recentemente pela Lei no 775/49 que regulamenta o ensino nas Escolas de Enfermagem do Brasil"(22). O mesmo diz ainda que a experiência vivenciada em campo prático é imprescindível para a formação da enfermeira psiquiátrica, e que tal conteúdo não pode ser aprendido em livros ou somente em aulas teóricas, pois afirmava que os melhores professores neste caso eram os próprios pacientes ${ }^{(22)}$.

Ao tornar obrigatório o estágio prático em diversas áreas, a Lei n775/49 promoveu o empreendimento de estratégias das escolas de enfermagem para se adequarem as suas exigências e cumpri-las. Até então, muitas escolas não tinham locais para que suas alunas estagiassem principalmente em psiquiatria, devido ao preconceito contra os doentes mentais, a falta de organização das instituições e a falta de preparo dos profissionais de enfermagem ${ }^{(8)}$. Em outro artigo publicado na revista Annaes de Enfermagem observamos a seguinte afirmativa: "Os doentes mentais não são bem tratados, porque não há, ainda, pessoas habilitadas para deles se ocuparem racionalmente. Vemos os hospitais repletos, mas quem, realmente trata dos pacientes? Pessoas simples, de pouca educação, sem cultura, mal remuneradas, com excesso de horas de trabalho, verdadeiros heróis, cheios de boa vontade ${ }^{(23)}$.

Desta forma, as escolas de enfermagem tiveram duas grandes preocupações: a de prover campos de estágio que fossem seguros para levar suas alunas, e a de especializar professores para acompanharem as alunas durante os estágios.

Waleska Paixão, diretora da EAN à época ${ }^{\ddagger}$ dizia que, para se falar na realização desses estágios deveriam ser levados em consideração dois pontos de vista: a sua importância para formar boas enfermeiras e a conveniência de serem todos eles realizados por todas as escolas. Diante das dificuldades encontradas, Waleska Paixão apontou que a Lei desconsiderava que nem todas as especialidades tinham campos de prática propício para o estágio de enfermagem, o que era o caso da psiquiatria: "Eliminemos pois a hipótese de serem todos os estágios indispensáveis à formação de boas profissionais. Nesse caso devemos desprezar as exigências legais dos estágios enumerados na regulamentação da lei 775... O que me parece excessivo é exigir tais estágios, quando a maioria das escolas não poderá realiza-los integralmente" ${ }^{\prime(3)}$.

Não obstante, no ano de 1950, a EAN inicia atividades práticas em Enfermagem Psiquiátrica no Centro Psiquiátrico Nacional (CPN), que tinha como diretor o médico Adauto Botelho. Neste período, já havia acontecido a total desativação do Hospício Nacional dos Alienados, sendo então transferidos todos os doentes para o CPN, que ficava no bairro do Engenho de Dentro ${ }^{(23)}$.Vale ressaltar que quando a EAN inicia seu estágio no CPN, este hospital já era campo de estágio da Escola de Enfermagem Alfredo Pinto (EEAP), tradicionalmente inserida no campo psiquiátrico desde a sua criação, como anexa ao Hospital Nacional de Alienados ${ }^{(7)}$. A professora da EAN responsável em acompanhar as alunas foi Maria Dolores Lins de Andrade, que não tinha experiência na área e, portanto, mantinha as alunas como observadoras da prática exercida pelas alunas e professoras da $\operatorname{EEAP}^{(5,19)}$.

O CPN era um hospital divido em blocos onde mulheres homens e crianças eram separadas, permitindo às alunas observarem apenas as crianças e mulheres, não sendo expostas diretamente aos homens que podiam ser imorais e perigosos colocando em risco a moral das alunas $^{(19)}$. Outra característica favorável que contribuiu para a escolha do CPN como primeiro campo prático foi o

\footnotetext{
‡ Waleska Paixão foi diretora da EEAN no período de 1950 - 1968, sua gestão coincidiu com a vigência da Lei $775 / 49^{(20)}$.

Rev. Eletr. Enf. [Internet]. 2015 jan./mar.;17(1):85-93. Disponível em: http://dx.doi.org/10.5216/ree.v17i1.23546. - doi: 10.5216/ree.v17i1.23546.
} 
fato do CPN ser um hospital que se adequava aos princípios da $\mathrm{LBHM}^{(23)}$.

As atividades da EAN no CPN duraram de 1950 a 1953, quando a professora Maria Dolores foi encaminhada pela EAN aos Estados Unidos para fazer especialização em Enfermagem Psiquiátrica, onde ficou até 1954. Nesse período, a disciplina "Enfermagem Psiquiátrica" foi ministrada pelas professoras Ana Jaguaribe da Silva Nava e Olga Salinas Lacorte ${ }^{(19,24)}$. Um dado que chama atenção na análise dos Históricos das Alunas é o fato da professora Ana Nava não constar como docente no período em que a professora Maria Dolores foi para os EUA fazer sua especialização, mas este fato aparece em depoimento cedido pela própria Ana Nava, onde ela diz que teve que passar um curto espaço de tempo como professora de "Enfermagem Psiquiátrica", substituindo a professora Maria Dolores, mesmo sem ter afinidade com a área, porque na época não se discutia uma ordem da diretora da escola ${ }^{(24)}$.

Outro dado que chama atenção é que a palavra estágio só vem aparecer no histórico das alunas em 1954, pois antes disso só se faz menção a uma divisão da disciplina de "Enfermagem Psiquiátrica" em T (teórica) e $\mathrm{P}$ (prática), ou seja, enquanto a EAN esteve no CPN, não houve registro de estágio e sim de aulas práticas, que eram ministradas em hospital psiquiátrico ${ }^{(20)}$. Esse cuidado da EAN com a não utilização do termo "estágio" demonstrava que as alunas não exerciam a assistência de enfermagem ao doente mental e sim observavam as alunas e professoras da EEAP, não tendo o CPN sido um campo de estágio de fato e sim um campo de observação da prática, pois durante o período que passaram no CPN as alunas estavam sob a supervisão de uma professora que não tinha experiência alguma em psiquiatria e que, portanto, não tinha condições de orientar as alunas.

Em 1954, com a professora Maria Dolores já especializada em Enfermagem Psiquiátrica, o CPN deixa de ser campo prático da EAN, que passa a utilizar o Instituto de Psiquiatria da Universidade do Brasil (IPUB) ${ }^{(5)}$. Os documentos estudados comprovam a contratação da professora Maria Dolores para a função de Regente da disciplina de "Enfermagem em Neuro-Psiquiatria" nos anos de 1951, 1952 e $1953^{(20)}$. A obrigatoriedade do estágio em enfermagem psiquiátrica gerou muitas discussões devido à dificuldade de prover campos de estágio para as alunas. Chegou-se a pensar na possibilidade de escolas serem fechadas caso não tivessem como realizar tais estágios exigidos na Lei ou até mesmo, diante das dificuldades de formar enfermeiras, desrespeitar a Lei e permanecer deficiente em relação aos estágios exigidos. Cabe ressaltar que, se era difícil prover campo de estágio para as disciplinas que tinham como campo prático hospitais gerais, o que dizer diante da realidade da psiquiatria, onde se tinha poucos hospitais e os que existiam funcionavam em condições precárias, desumanas, sendo vistos como um local inapropriado para alunas $^{(3)}$.

Muitas escolas recorreram às filiações para resolver tais problemas como sugere a diretora Waleska Paixão quando diz: "Enquanto não conseguirmos, que cada escola aperfeiçoe aqueles [campos de estágio] de que dispõe, recorram a outras escolas, quando possível para filiação"(3). Outra solução encontrada pela diretora foi: "Colaborar na remodelação dos atuais centros de Psiquiatria, de ortopedia, de doenças transmissíveis para facilitar os estágios das escolas mais próximas”(3).

Sendo assim, a atitude adotada pela EAN foi iniciar uma remodelação do ensino de Enfermagem Psiquiátrica e a preparação do hospital psiquiátrico da universidade a qual pertencia, o IPUB, para ser centro de filiação para as demais escolas de enfermagem do Brasil.

O ensino de Enfermagem Psiquiátrica não recebia nas escolas de enfermagem o caráter essencial que possuía outras disciplinas como pediatria, clínica médica, ortopedia, entre outras, haja vista que foi necessária a promulgação de uma Lei para que se tornasse matéria obrigatória e com estágio no currículo das Escolas de Enfermagem do país, bem como para que o interesse em relação a área fosse despertado.

As questões referentes ao ensino de Enfermagem Psiquiátrica começaram a ser mais discutidas a partir de 1950 quando o estágio passou a ser obrigatório. A Lei 775/49 em muito influenciou o desenvolvimento da Enfermagem Psiquiátrica na EAN, pois levou a diretora à época a buscar estratégias para o desenvolvimento do ensino teórico e prático dessa disciplina. Podemos destacar a ida da EAN para o CPN e o aperfeiçoamento de uma professora em curso de especialização nos Estados Unidos, trazendo a devida qualificação para o ensino da Enfermagem Psiquiátrica na EAN, após a promulgação da Lei. Ao possuir uma professora especialista em enfermagem psiquiátrica a EAN sai do CPN e inicia a adequação do IPUB para ter seu próprio campo de estagio qualificado $^{(5)}$.

\section{CONSIDERAÇÕES FINAIS}

Quando se estuda a trajetória do ensino de uma especialidade como a enfermagem psiquiátrica, nos deparamos com o lento processo de transição das práticas na área e percebemos que o ensino de enfermagem foi 
influenciado diretamente por esta lentidão. Ainda hoje, em pleno movimento de Reforma Psiquiátrica, nos deparamos com questões que refletem o estigma relacionado à doença mental e seu reflexo no processo de formação de enfermeiros.

Ao se pesquisar a gênese do ensino de enfermagem psiquiátrica na EAN, nos deparamos com o fato de que esta escola, embora tenha sido legalmente modelo de ensino no país, levou 27 anos para entrar no campo psiquiátrico. O desenvolvimento do ensino referente à psiquiatria no currículo da escola iniciou com a teoria e reconhecimento do saber médico até chegar na observação da prática, ensinada e exercida por outra escola e, finalmente, ao estágio propriamente dito. O dispositivo que levou ao início do estágio em Psiquiatria na EAN e em muitas escolas de enfermagem do país foi a Lei $n^{\circ} 775 / 49$. As primeiras alunas tiveram como campo de estágio o CPN, onde, como a professora, ficavam mais na observação da prática de alunas e professoras da Escola Alfredo Pinto, que já tinha o CPN como campo de estágio. Tal estratégia demonstra que a EAN preocupavase em cumprir a Lei, mas se preocupava com a preservação física e moral das suas alunas e com a qualidade do ensino oferecido pelo corpo docente, problema este solucionado com o envio da professora Maria Dolores aos EUA para fazer um curso de especialização em enfermagem psiquiátrica. O estudo possibilitou a identificação ainda que outra estratégia da EAN foi transferir o estágio do CPN para o IPUB onde teria maior autonomia, uma vez que o IPUB como a escola pertencia a UB.

Sendo assim, esta pesquisa permitiu uma reflexão sobre o ensino de enfermagem psiquiátrica na atualidade, a partir do conhecimento de estratégias implantadas por uma escola de enfermagem na primeira metade do século XX. Esta reflexão torna-se possível devido à dificuldades comuns em todas as época para o desenvolvimento do ensino de enfermagem psiquiátrica, especialmente, para o ensino em campo prático, e ratifica a necessidade de professores especializados e devidamente preparados.

\section{REFERÊNCIAS}

1. Carvalho V. Cuidando, pesquisando e ensinando: acerca de significados e implicações da prática da enfermagem. Rev. latinoam. enferm. 2005; 12(5):806-15.

2. Budó MLD, Saupé R. Conhecimentos Populares e Educação em Saúde na Formação do Enfermeiro. Rev Bras Enfermagem. 2004; 57(2):165-9.

3. Paixão W. Conveniência dos estágios previstos na Lei 775. Anais de Enfermagem. 1951;IV(4): 45-51.

4. Magnago C, Tavares CMM. O ensino de enfermagem psiquiátrica nas Universidades Públicas do Estado do Rio de Janeiro. Rev. Eletr. Enf. [Internet]. 2012 [acesso em 02 mar 2013]; 14 (1): 50-8. Disponível em:

http://www.fen.ufg.br/fen_revista/v14/n1/pdf/v14n1a06.pdf. 5. Peres MAA, Barreira IA. Uma nova enfermagem psiquiátrica na Universidade do Brasil nos anos 60 do século XX. Esc. Anna Nery. $2008 ; 12(1)$ : 108-14.

6. Santos TCF, Barreira IA, Fonte AS, Oliveira AB. Participação americana na formação de um modelo de enfermeira na sociedade brasileira na década de 1920. Rev esc enferm USP. $2011 ; 45(4)$ : 966-73.

7. Geovanini T, Moreira A, Schoeller SD, Machado WCA. Desmitificando a origem da enfermagem brasileira. In: Geovanini T, Moreira A, Schoeller SD, Machado WCA. História da Enfermagem - versões e interpretações. Rio de Janeiro: Revinter; 2002.

8. Pereira MM, Padilha MI, Oliveira AB, Santos TCF, Almeida Filho AJ, Peres MAA. Discursos sobre o modelo de enfermagem e de enfermeira psiquiátrica nos Annaes de Enfermagem (19331951). Rev Gaúcha Enferm. 2014; 35 (2):47-52.

9. Kirschbaum DIR. Análise Histórica das Práticas de Enfermagem no campo da Assistência Psiquiátrica no Brasil, no período compreendido entre as décadas de 20 e 50. Rev LatinoAm Enferm. 1997; 5(Supl.):19-30.

10. Coimbra VCC, Guimarães J, Silva MCF, Kantorsi L, Scatena MCM. Reabilitação psicossocial e família: Consideração sobre a reestruturação da reforma Psiquiátrica no Brasil. Rev. Eletr. Enf. [Internet]. 2005 [acesso em 21 abr 2013]; 7(1): 99-104. Disponível em:

http://www.fen.ufg.br/fen_revista/revista7_1/revisao_01.htm.
11. Kantorski LP. A Reforma Psiquiátrica - um estudo parcial acerca da produção científica. Rev. Eletr. Enf. [Internet]. 2001 [acesso em 14 dez 2012]; 3(2). Disponível em: http://www.fen.ufg.br/fen_revista/revista7_1/revisao_01.htm. 12. Castro H. História Social. In Cardoso CF, Vainfas R. Domínios da História- Ensaios de Teoria e Metodologia. Rio de Janeiro: Campos; 1997.

13. Miranda CML. O Parentesco Imaginário: história e representação social da loucura do espaço asilar. Rio de Janeiro: Cortez; 1994.

14. Tyrrel MAR, Santos TCF. Setenta Anos de Vida Universitária da Escola de Enfermagem Anna Nery: Uma Breve Reflexão. Esc. Anna Nery. 2007; 11(1): 138-42.

15. Saíde OL. Psiquiatria e organização do Estado Brasileiro. [dissertação] Rio de Janeiro (RJ): Instituto Biomédico/UERJ; 1980.

16. Olinto P. Aptidões e deveres da enfermeira de Hygiene Mental. Revista Annaes de Enfermagem. 1933; 1(2):16-17. 17. Canabrava DS, Souza TS, Fogaça MM, Guimarães AN, Borille DC, Vilella JC, et al. Tratamento em saúde mental: estudo documental da legislação federal do surgimento do Brasil até 1934. Rev. Eletr. Enf. [Internet]. 2010 [acesso em: 18 mar 2012]; 12(1):170-6. Disponível em: http://www.fen.ufg.br/revista/v12/n1/v12n1a21.htm. 18. Peres MAA, Barreira IA, Santos TCF, Almeida Filho AJ, Oliveira $A B$. O ensino de psiquiatria e o poder disciplinar da enfermagem religiosa: o Hospício de Pedro II no segundo reinado. Texto \& Contexto Enferm. 2011; 20(4):700-08. 19. Andrade, MDL. Depoimento oral. Rio de Janeiro, Centro de Documentação da EEAN, Acervo de História Oral, 1990. Dois cassetes sonoros (ca. $120 \mathrm{~min}$ ).

20. Escola Anna Nery (EAN). Histórico da vida Escolar Das Alunas. Ano: 1923 a 1961 . Rio de Janeiro. Centro de documentação da Escola de Enfermagem Anna Nery; Cx: 07 a 47; mod. GR; Ano: 1923-1961.

21. Lei n.775 de 6 agosto de 1949. Dispõe sobre o ensino de enfermagem no país e dá outras providências. Diário Oficial da União [Internet]. 1949 [acesso em 21 jan 2011]. Disponível em: http://www2.camara.leg.br/legin/fed/lei/1940-1949/lei-775-6agosto-1949-363891-publicacaooriginal-1-pl.html. 
22. Carvalho A. O paciente mental agitado. Revista Annaes de Enfermagem. 1947; 16(23): 24-25.

23. Barcellos E. Enfermagem Psiquiátrica. Revista Annaes de Enfermagem. 1951; 4(1): 86-89.

24. Baptista SS, Barreira IA. Anna Nava, baluarte da Escola Anna

Nery (anos 1940/1970). Esc. Anna Nery. 2009;13(3):543-51.

Artigo recebido em 06/04/2013.

Aprovado para publicação em 10/06/2014.

Artigo publicado em 31/03/2015. 